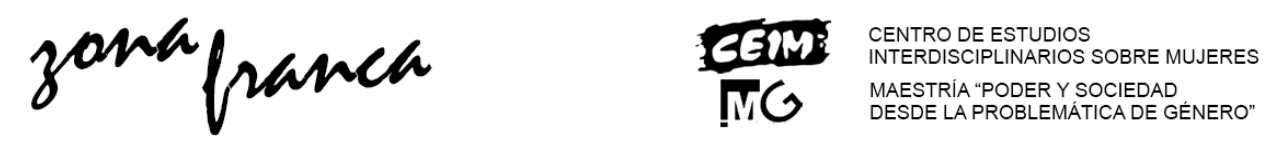

\title{
Indeso-Mujer, la historia de un legado feminista en Rosario
}

\author{
Betiana Spadillero Gaioli ${ }^{*}$
}

\section{Introducción}

El Instituto de Estudios Jurídico-Sociales de la Mujer (Indeso-Mujer) es una organización feminista de Rosario, creada en 1984 por un grupo de mujeres profesionales y militantes sociales; algunas de las cuales regresaron a la Argentina luego de tener que permanecer exiliadas en el extranjero durante la última dictadura cívico-militar. Ese grupo fundador estaba compuesto por Susana Chiarotti, Mabel Gabarra y Mimí Chiarotti. Desde ese año, nuestra institución trabaja por el reconocimiento de los derechos de las mujeres; y la prevención de toda forma de discriminación y violencia basadas en el género.

La intención del presente artículo es recuperar la historia de esta asociación civil sin fines de lucro, que supo tomar las demandas de las mujeres y convertirlas en sus banderas de lucha cotidiana. Son 36 años de militancia sin interrupciones, renovando estrategias y desafíos a cada paso; por ello, no es una tarea sencilla relatar su trayectoria. Sin embargo, tomamos el compromiso de plasmar algunos de los momentos y proyectos más significativos. $\mathrm{Y}$, de antemano, pedimos disculpas por aquello que quedó en el tintero: todas las anécdotas, logros y emociones compartidas que no caben en algunas páginas.

Antes de comenzar, es importante señalar que desde su fundación en Indeso-Mujer bregamos por una serie de principios básicos: la construcción de una sociedad más justa, equitativa, respetuosa de la diversidad, solidaria y

*Responsable de la comunicación institucional en Indeso-Mujer. Lic. en Comunicación Social y Mg. en Poder y Sociedad desde la Problemática del Género. Contacto: betianaspadillero@gmail.com

Revista Zona Franca- Centro de estudios interdisciplinario sobre las mujeres (CEIM)- Maestría poder y sociedad desde la problemática de género (MG), Rosario, Argentina. ISSN, 2545-6504 http://zonafranca.unr.edu.ar/index.php/ZonaFranca| Número 28 (2020). 
democrática. Somos un espacio de participación, intervención, formación, reflexión, capacitación y comunicación que aporta a la modificación de las relaciones de subordinación existentes.

Rosario tiene una historia de militancia muy importante, de la que hemos sido partícipes de manera activa. Formamos parte del movimiento de mujeres a nivel local, nacional y también regional, como integrantes de la Plataforma Mercosur Social y Solidario (PMSS). Trabajamos en forma articulada con otros colectivos feministas y espacios de educación (formal y no formal) en diferentes territorios; realizando talleres, encuentros de formación, intervenciones urbanas, y otras instancias de sensibilización y visibilización de derechos.

Entre los logros destacados de estos años, podemos mencionar: aportar en la elaboración y cumplimiento de leyes vinculadas a los derechos de las mujeres e infancias (Ordenanza №8667/2010 contra la Trata de Personas, Ordenanza № 8729/2010 de creación de la Mesa de Trabajo Contra la Trata de Personas, Ordenanza №7125/2000 de creación del Programa Integral para la Prevención y Detección Temprana del Abuso Sexual y Maltrato Infantil); llevar adelante una investigación en torno al Presupuesto Sensible al Género (PSG) en Rosario en 2012; formar parte de la Campaña por la ESI; realizar capacitaciones a funcionarios/as públicos en perspectiva de género; elaborar materiales educativos y de sensibilización (en formato papel y audiovisual) sobre las temáticas que trabajamos; brindar un espacio de asesoramiento integral gratuito a mujeres víctimas de violencia; tener una biblioteca feminista y de organizaciones sociales.

A continuación, ahondaremos en algunos hitos significativos de nuestra historia:

\section{Primero pasos}

En 1983, con el retorno democrático en nuestro país comenzaron a surgir nuevos modos de participación social y política. En ese marco, un grupo de

Revista Zona Franca- Centro de estudios interdisciplinario sobre las mujeres (CEIM)- Maestría poder y sociedad desde la problemática de género (MG), Rosario, Argentina. ISSN, 2545-6504 http://zonafranca.unr.edu.ar/index.php/ZonaFranca| Número 28 (2020). 
militantes que volvieron al país decidieron conformar en Rosario una oficina jurídica en defensa de los derechos de la mujer trabajadora. Luego, con los movimientos particulares y de contexto, el perfil institucional se vio transformado; priorizando el trabajo por la eliminación de todas las formas de discriminación contra las mujeres.

Cabe destacar que en los ' 80 hubo modificaciones en el sistema de trabajo y la crisis económica fue tomada de diferentes formas entre varones y mujeres. Las mujeres nos incorporamos en forma masiva al mercado de trabajo, produciendo transformaciones en la organización doméstica. Incluso ante la crisis económica, fuimos quienes protagonizamos estrategias de sobrevivencia en los barrios como las ollas populares, centros comunitarios, implementación de los trueques; así como la institucionalización de esas prácticas, con la generación de organizaciones gubernamentales y no gubernamentales de servicios.

Con el paso del tiempo, el perfil de Indeso-Mujer se fue ampliando asumiendo los siguientes ejes temáticos: violencia contra la mujer, derechos humanos, equidad de género e igualdad de oportunidades, salud, sexualidad, educación, construcción de ciudadanía, democracia participativa, entre otros. El objetivo continúa siendo incorporar la perspectiva de género en todas las actividades, y trabajar en la promoción y defensa de los derechos de las mujeres.

Entendemos que lograr la equidad de género presupone, por un lado, reconocer la desigualdad que se expresa en múltiples subordinaciones y discriminaciones de y hacia las mujeres; y por otro, tender a la construcción de una sociedad más justa y solidaria, donde la relación equitativa entre los sexos sea una realidad. Nuestra organización está coordinada por un equipo de mujeres de diversas profesiones, al que se le suman colaboradoras en determinados proyectos y actividades.

Históricamente contamos con áreas institucionales que han visto fortalecido su funcionamiento dependiendo de la demanda y el contexto: formación y

Revista Zona Franca- Centro de estudios interdisciplinario sobre las mujeres (CEIM)- Maestría poder y sociedad desde la problemática de género (MG), Rosario, Argentina. ISSN, 2545-6504 http://zonafranca.unr.edu.ar/index.php/ZonaFranca| Número 28 (2020). 
capacitación, asesoría y asistencia, comunicación, participación y tareas de lobby, promoción comunitaria, y biblioteca.

\section{El Centro de Mujeres "Juana Azurduy"}

Una apuesta territorial y de promoción comunitaria que marcó la historia de Indeso-Mujer, fue el Centro de Mujeres "Juana Azurduy", emplazado en el barrio Empalme Graneros' de Rosario. El mismo tenía como propósito ser un lugar de encuentro para las mujeres de la zona; donde entre todas se avanzara en el conocimiento de los problemas comunes, se compartieran las preocupaciones y se sumaran esfuerzos para mejorar sus condiciones de vida.

La iniciativa surgió después de una inundación del barrio en 1986, a causa del desborde del Arroyo Ludueña. En solidaridad a esta situación, se realizó una campaña de recolección de ropa, pañales y alimentos que se concentraban en la Asociación Rural de la ciudad. Fue entonces cuando integrantes de Indeso-Mujer se encontraron con mujeres del barrio, con quienes habían compartido espacios de militancia en los ‘70, previo al Golpe de Estado de 1976.

A partir de dicho encuentro, se decidió constituir un espacio comunitario para el abordaje de los derechos de las mujeres de ese barrio. La inauguración tuvo lugar el 13 de julio de 1987 y la dirección del Centro quedó a cargo de una Comisión de mujeres de la zona, a la cual nuestra organización prestaba colaboración económica y asesoramiento (Gabarra 1995).

En la revista "Reconociendo nuestra realidad" (Selva 1989), se menciona que el Centro fue creciendo hasta contar con: un consultorio jurídico, el puesto de enfermería, atención ginecológica y psicológica, apoyo en educación y el funcionamiento de un "roperito". A su vez, se realizaban talleres en los que se

I Empalme Graneros es un barrio popular, ubicado al noroeste de Rosario. Su límite norte es el Arroyo Ludueña, cuyos desbordes inundaban la zona en forma periódica por esos años. El Centro de Mujeres "Juana Azurduy" estaba ubicado sobre terrenos fiscales, en el corazón de una villa de emergencia.

Revista Zona Franca- Centro de estudios interdisciplinario sobre las mujeres (CEIM)- Maestría poder y sociedad desde la problemática de género (MG), Rosario, Argentina. ISSN, 2545-6504 http://zonafranca.unr.edu.ar/index.php/ZonaFrancal Número 28 (2020). 
compartían experiencias en torno a temáticas comunes, como la violencia de género, la sexualidad y la situación de las mujeres trabajadoras.

Sobre este último aspecto, una encuesta realizada por el equipo de IndesoMujer entre 1988 y 1989", da cuenta de algunos datos significativos. El relevamiento en 85 hogares del barrio"I, mostró que las mujeres expresaron dedicarse "solamente" a las tareas del hogar; aunque 3 de cada 10 se desempeñaba en alguna actividad remunerada, pero invisibilizada o considerada de menor rango que la de los varones del grupo familiar.

Otro dato que llamó la atención fue que la mayoría de las mujeres no recibían jubilación o pensión: "Las condiciones de marginación de la vejez surgen como acuciantes para las mujeres, que sobreviven con las escasas ayudas de hijos y parientes", se remarcó en la publicación citada.

En análisis posteriores realizados por equipos interdisciplinarios de IndesoMujer, se marcaron otros indicadores de relevancia para el barrio: el sistema de educación presentaba problemas de inclusión para las mujeres; las instituciones comunitarias mostraban debilidades por falta de recursos materiales y profesionales; y las familias atravesaban fuertes procesos de desafiliación y empobrecimiento, producto de la crisis socioeconómica. Además, en forma transversal, la violencia se manifestaba tanto a nivel familiar como social, siendo expresada a través de la discriminación por diferencias de género, sexo, clase social o cultura.

En 1990, a través del Programa Promin, se desarrollaron actividades de promoción de la salud y se puso en funcionamiento el Centro de Salud Municipal "Juana Azurduy". Algunas de las políticas públicas que atravesaban el Centro de Mujeres en esa época fueron: Plan Jefes y Jefas de Hogar Desocupados, Plan

\footnotetext{
"Las entrevistas se llevaron adelante con la intención de devolver información organizada sobre tres ejes temáticos: familia, educación y trabajo; acercando una mirada más global sobre las condiciones de vida del barrio.

III La población de Empalme Graneros se caracteriza por ser, en su mayoría, oriunda del Chaco, con altos niveles de analfabetismo, desocupación y necesidades básicas insatisfechas.
}

Revista Zona Franca- Centro de estudios interdisciplinario sobre las mujeres (CEIM)- Maestría poder y sociedad desde la problemática de género (MG), Rosario, Argentina. ISSN, 2545-6504 http://zonafranca.unr.edu.ar/index.php/ZonaFrancal Número 28 (2020). 
Manos a la Obra, Copa de Leche, Programa PAEBA (de alfabetización y educación básica para adultos), y Programa Volver a la Escuela.

Las actividades en el barrio se llevaron adelante en articulación con otras instituciones, tales como centros de salud, centros comunitarios, comedores y escuelas. Sin embargo, el sostenimiento de las mismas se complejizó a fines de 2010, debido a la falta de financiamiento de algunos proyectos, el aumento de la inseguridad en el barrio, entre otros conflictos.

En documentos institucionales de noviembre de ese año, quedó asentada esta preocupación por la disminución de la concurrencia de las mujeres al Centro, debido a los permanentes robos y hechos delictivos en el barrio. En ese marco, se definió el traspaso del espacio a la Municipalidad para que lleve adelante actividades de índole social, principalmente vinculadas con jóvenes y el consumo problemático de drogas.

\section{Apuesta a la integración regional: de Amuyen a la PMSS}

Desde sus orígenes, nuestra organización se propuso trabajar en forma articulada con otros colectivos y espacios. En una entrevista al programa radial "Feminismos del Sur" (2018), una de las fundadoras de Indeso-Mujer Noemí "Mimi" Chiarotti, relató que un paso fundamental fue la conformación de la Red Amuyen.

La misma estaba integrada por ocho organizaciones de diferentes provincias argentinas: Santa Fe, Buenos Aires y Mendoza. En esa línea, recordó:

"Esto fue posterior a los '90. Es decir, que el liberalismo en Argentina nos
había dejado muy mal económicamente, con mucha desocupación y
pobreza, con una disminución de nuestros derechos porque había
flexibilización laboral. Entonces, nos vimos en la necesidad de unir
fuerzas. Fue muy interesante, porque había grupos de educación
popular, de defensa de los derechos humanos, campesinos, los que

Revista Zona Franca- Centro de estudios interdisciplinario sobre las mujeres (CEIM)- Maestría poder y sociedad desde la problemática de género (MG), Rosario, Argentina. ISSN, 2545-6504 http://zonafranca.unr.edu.ar/index.php/ZonaFrancal Número 28 (2020). 
trabajaban por el derecho a la vivienda, y nosotras que trabajábamos con mujeres".

Asimismo, remarcó que la idea era que las organizaciones asumieran todos los puntos que se estaban trabajando. "Por ejemplo, los derechos de las mujeres no es una camisa que te ponés cuando salís de tu casa, es algo que lo tenés que tener metido. $Y$ las organizaciones sociales tienen tratos discriminatorios con respecto a las mujeres de su misma organización", subrayó.

La militante hizo hincapié en la naturalización de estas formas machistas:

\begin{abstract}
"Cuando conformamos esta Red, parecía que lo que nosotras defendíamos era de menor valuación que el resto de los temas. Nos costó bastante que se valorice nuestra perspectiva. ¿Qué fue lo que nos ayudó? Primero, los Encuentros Nacionales de Mujeres donde teníamos nuestro lugar de reunión anual. Segundo, el Foro Social Mundial también aportó una mirada más estratégica, para poder oponernos al neoliberalismo que se había impuesto en la región".
\end{abstract}

Desde Amuyen se llevaron adelante una serie de proyectos y, a su vez, se empezaron a trazar alianzas con organizaciones de otros países (Uruguay, Brasil, Paraguay y Chile), con las cuales se conformó posteriormente la Plataforma Mercosur Social y Solidario'v (PMSS).

La PMSS nació en 2004 con la impronta de sumar y hacer visible el trabajo territorial de las organizaciones y movimientos sociales de cinco países del Mercosur. En casi dos décadas de funcionamiento, hemos aportado a la profundización y democratización del proceso de integración regional.

Nos hemos constituido en un espacio de reflexión, análisis y capitalización de un conjunto de prácticas sociales y políticas. Además, producimos herramientas que sistematizan experiencias y procesos, para ser compartidos con otras

IV En la página web de la Plataforma Mercosur Social y Solidario (PMSS) se pueden encontrar artículos de interés, documentos y producciones colectivas. Disponible en http://www.mercosursocialsolidario.org/

Revista Zona Franca- Centro de estudios interdisciplinario sobre las mujeres (CEIM)- Maestría poder y sociedad desde la problemática de género (MG), Rosario, Argentina. ISSN, 2545-6504 http://zonafranca.unr.edu.ar/index.php/ZonaFrancal Número 28 (2020). 
organizaciones como ámbitos privilegiados de nuestra intervención educativapolítica.

Como organización feminista, Indeso-Mujer forma parte del Eje Derechos de las Mujeres al interior de la Plataforma (la cual se organiza además bajo los ejes temáticos soberanía alimentaria, juventudes y economía social). Desde 2010, nuestra estrategia de acción se centró en las violencias extremas y la trata de personas con fines de explotación sexual; visibilizada como el emergente territorial de un problema social que crece exponencialmente en la región.

Entre las acciones destacadas, podemos nombrar los "Encuentros de Frontera sobre Trata de Personas" llevados a cabo en distintos puestos entre países limítrofes (Rivero y Olivera 2016). Entre 2011 y 2016, se realizaron ocho talleres cuya característica más valorada fue haber estado pensados, diseñados y convocados por organizaciones sociales en articulación con organismos internacionales y/o programas de los gobiernos de los países intervinientes.

Otro producto relevante del trabajo del Eje ha sido la elaboración y actualización de la "Valija Pedagógica sobre Trata de Personas"V. Un conjunto de herramientas conceptuales, didácticas y metodológicas que permiten abordar esta problemática. Los materiales incluidos posibilitan el conocimiento de este flagelo, desde documentos, libros, informes, normativas; así como el modo de trabajarlo tanto desde las instituciones como desde los Estados.

\section{Pioneras por el derecho a decidir}

Historizar en torno a la Campaña por el Derecho al Aborto Legal, Seguro y Gratuito en Argentina es apasionante, porque involucra compromisos y desafíos que marcaron la escena de discusión política en toda la región. Rastreando en el archivo de Indeso-Mujer podemos encontrar muchos materiales que dan cuenta de los primeros años del 2000, cuando el debate se empezó a instalar con más

₹ La "Valija Pedagógica" está disponible en http://valijapedagogica.mercosursocialsolidario.org/

Revista Zona Franca- Centro de estudios interdisciplinario sobre las mujeres (CEIM)- Maestría poder y sociedad desde la problemática de género (MG), Rosario, Argentina. ISSN, 2545-6504 http://zonafranca.unr.edu.ar/index.php/ZonaFrancal Número 28 (2020). 
fuerza. Entonces, las integrantes de nuestra organización eran parte activa de ese movimiento, lo que hoy conocemos como "marea verde".

Uno de los hitos de la conformación de la Campaña tuvo lugar en el $18^{\circ}$ Encuentro Nacional de Mujeres realizado en 2003 en Rosario. Así lo expresa un boletín sobre el "Primer Encuentro Nacional por el Derecho al Aborto", llevado a cabo en Buenos Aires el 29 de mayo de 2004:

"De ese Encuentro en el que miles de mujeres desfilaron tras la consigna 'anticonceptivos para no abortar, aborto legal para no morir' y sostuvieron en los talleres su posición a favor del derecho a decidir sobres sus cuerpos, su sexualidad y su vida; surgió la iniciativa de convocar a una reunión nacional en la que se acordaran estrategias para conseguir que el acceso a abortos legales y seguros sea una posibilidad real para todas las mujeres y no un privilegio de las que tienen medios económicos" (pág. 3).

El cuadernillo de síntesis, menciona asimismo a las integrantes del "Grupo Estrategias por el Derecho al Aborto" que se constituyó en esa época para generar una articulación a nivel nacional. Indeso-Mujer aparece entre las organizaciones del interior del país que apoyaban y adherían a estas acciones.

Incluso, algunos artículos recuperan que nuestra institución participó y convocó diversas actividades, algunas de las cuales datan de principios de los '90 Vl: presentación de libros, charlas, posicionamientos en medios de comunicación, son tan sólo algunas de ellas. Así es que en septiembre de 2003, por ejemplo, se realizó en Rosario la "Semana por la Despenalización del Aborto" tomando como marco el "Día de Acción Global por el Acceso al Aborto Legal y Seguro" (que se celebra el 28 de septiembre).

VI En septiembre de 1990, las entonces integrantes de Indeso-Mujer Mabel Gabarra y Susana Chiarotti participaron de un polémico debate en el programa de Radio Hipótesis. Las militantes feministas defendieron el derecho a decidir de las mujeres, frente a posturas conservadoras de los ginecólogos Rafael Luis Pineda y Julio César Colabianchi, el pastor evangélico Jorge Ramos y el endocrinólogo Orlando Prendes. El debate es reproducido en la publicación $N^{\circ} 6$ "Club de Hipótesis" de noviembre de 1990.

Revista Zona Franca- Centro de estudios interdisciplinario sobre las mujeres (CEIM)- Maestría poder y sociedad desde la problemática de género (MG), Rosario, Argentina. ISSN, 2545-6504 http://zonafranca.unr.edu.ar/index.php/ZonaFrancal Número 28 (2020). 
Al año siguiente, otro hito fue el $19^{\circ}$ Encuentro Nacional de Mujeres, realizado en la ciudad de Mendoza, que incluía en el temario de talleres "Anticoncepción y aborto". Una nota de opinión de Marta Dillon (2004) recuerda ese histórico y masivo Encuentro:

"Como colectivo nos pronunciamos otra vez a favor de la despenalización del aborto, como una herramienta fundamental para que las mujeres tengan derecho a decidir sobre sus propios cuerpos. Pero la violenta intervención de sectores fundamentalistas católicos exige debatir sobre el modo de preservar este espacio democrático, que se ha ido ampliando a lo largo de dos décadas".

Otro paso importante fue instalar esta demanda en la movilización por el "Día de la Mujer Trabajadora". En un artículo publicado el 8 de marzo de 2005en el diario La Capital, titulado "La despenalización del aborto, eje del reclamo en el Día de la Mujer", se indica:

"No es casual que uno de los principales reclamos de la marcha gire en torno a la despenalización del aborto. De hecho, hace años que las mujeres de Rosario se encargan de promover un 'aborto legal y gratuito'. Pero esta vez la reivindicación se producirá en un contexto particular: el pronunciamiento del ministro de Salud de la Nación, Ginés González García, y el de la cartera sanitaria de la provincia, Juan Héctor SylvestreBegnis, a favor de que no se penalice esta práctica".

La nota también cita declaraciones de las militantes Mabel Gabarra (IndesoMujer) y Liliana Pauluzzi (Casa de la Mujer), exigiendo respuestas urgentes de los Estados.

Más adelante, Sonia Tessa en un artículo de mayo de 2005 relata cómo empezó la Campaña en Rosario, y describe una de las instancias de visibilización de la militancia local: juntar firmas en la vía pública. Allí estaban algunas feministas reconocidas como Viviana Della Siega (Insgenar), Susana Moncalvillo y Mabel Gabarra (éstas últimas integrantes de Indeso-Mujer).

Revista Zona Franca- Centro de estudios interdisciplinario sobre las mujeres (CEIM)- Maestría poder y sociedad desde la problemática de género (MG), Rosario, Argentina. ISSN, 2545-6504 http://zonafranca.unr.edu.ar/index.php/ZonaFrancal Número 28 (2020). 
En ese petitorio, se exigía que "las mujeres que deciden interrumpir un embarazo tengan atención segura y gratuita en todos los hospitales y obras sociales del país". La nota periodística citaba una encuesta de la Fundación Friedrich Ebert, que reflejaba que el $60 \%$ de la población estaba de acuerdo con la interrupción de un embarazo si era producto de una violación o cuando la vida intrauterina era inviable.

La Campaña Nacional por el Derecho al Aborto Legal Seguro y Gratuito se lanzó oficialmente el 28 de mayo de 2005, "Día de Internacional de Acción por la Salud de las Mujeres". La contratapa del Periódico "Otras Voces" (Indeso-Mujer 2005), de mayo de ese año, tomaba un reclamo que sigue vigente:

"La clandestinidad del aborto no impide su realización sino que aumenta los riesgos y atenta contra la dignidad de las mujeres y de toda la sociedad. No queremos ni una sola muerte más por abortos clandestinos".

Desde entonces, la Campaña tiene la capacidad y la fuerza de coordinar actividades simultáneamente en distintos puntos del país bajo la consigna: "Educación sexual para decidir, anticonceptivos para no abortar, aborto legal para no morir". Actualmente, cuenta con la adhesión de 305 grupos, organizaciones y personalidades vinculadas a organismos de derechos humanos, de ámbitos académicos y científicos, trabajadoras/es de salud, sindicatos y diversos movimientos sociales y culturales.

Según detalla la página web de la Campaña VII, la apuesta colectiva converge "en una gran heterogeneidad de actividades y procesos estratégicos para: instalar en la sociedad y en el Estado el debate en torno a la necesidad de despenalizar y legalizar el aborto; contribuir a que más mujeres y organizaciones se sumen en este proceso; lograr el debate y la aprobación de una norma legal en Argentina".

\footnotetext{
VII La Campaña Nacional por el Derecho al Aborto Legal, Seguro y Gratuito tiene una página oficial donde difunde actividades, artículos y proyectos. Disponible en http://www.abortolegal.com.ar
}

Revista Zona Franca- Centro de estudios interdisciplinario sobre las mujeres (CEIM)- Maestría poder y sociedad desde la problemática de género (MG), Rosario, Argentina. ISSN, 2545-6504 http://zonafranca.unr.edu.ar/index.php/ZonaFrancal Número 28 (2020). 
El proyecto de la Campaña para la Interrupción Voluntaria del Embarazo (IVE) ya se presentó ocho veces en el Congreso de la Nación. En 2018 obtuvo la media sanción en Diputados, en lo que fue un año sin precedentes para la lucha por este derecho.

En 2020, en el marco del "Día de Acción Global por el Acceso al Aborto Legal y Gratuito", se publicó una solicitada instando a todas las fuerzas políticas a aprobar la ley de IVE de "manera urgente". "En la Argentina se realizan aproximadamente 54 abortos por hora. Según las últimas estadísticas oficiales, 39.025 mujeres y niñas ingresaron en hospitales por complicaciones de salud relacionadas con abortos en un solo año", cita el comunicado.

En marzo pasado, el Presidente Alberto Fernández había anunciado en la apertura de sesiones ordinarias la presentación de un proyecto para "legalizar" la interrupción voluntaria del embarazo. "Un Estado que cuida debe acompañar a todas las mujeres para que estos procesos se desarrollen accediendo plenamente al sistema de salud", aseguró en ese marco.

No obstante, todavía no hubo avances en este sentido arguyendo la crisis sanitaria que atraviesa el país (y el mundo) ante la pandemia por Covid-19. En una nota del 19 junio de 2020 publicada en Infobae y titulada "Alberto Fernández aseguró que postergó el envío de la ley de aborto al Congreso por la pandemia de coronavirus", el primer mandatario afirmó que:

"Las prioridades siguen siendo las mismas, hay que seguir trabajando para mejorar las condiciones de igualdad, para darle a la mujer los derechos que tienen; yo no he abdicado en mandar la ley de aborto, en absoluto, simplemente postergamos el envío por la urgencia que hoy tenemos".

Mientras tanto, el último proyecto presentado por la Campaña todavía tiene estado parlamentario y las mujeres siguen más unidas que nunca en este reclamo.

\section{La ESI, como un pilar fundamental}

Revista Zona Franca- Centro de estudios interdisciplinario sobre las mujeres (CEIM)- Maestría poder y sociedad desde la problemática de género (MG), Rosario, Argentina. ISSN, 2545-6504 http://zonafranca.unr.edu.ar/index.php/ZonaFrancal Número 28 (2020). 
Desde Indeso-Mujer reivindicamos a la Educación Sexual Integral (ESI) como un instrumento fundamental. La ESI ofrece herramientas para conocer el propio cuerpo; respetar la diversidad; poder expresar dudas sobre diferentes etapas de cambios y desarrollo; respetar la intimidad, los vínculos y las emociones; prevenir situaciones de violencia y abuso; entre muchos otros temas y preocupaciones.

Profundizar su incorporación y apropiación requiere de un trabajo en red desde los diferentes ámbitos; logrando remover diversos obstáculos y resistencias tanto personales como institucionales.

Consideramos que no es posible lograr un abordaje integral de la sexualidad a partir sólo de los esfuerzos individuales (Indeso-Mujer 2019). Por ello, resulta vital su efectiva implementación en todo el sistema educativo, en todos los niveles; que se incluyan el ámbito de la salud y los espacios de desarrollo territorialcomunitario; que en el ámbito legislativo se logre una ampliación y reglamentación de derechos; y que en el ámbito judicial se incorpore la perspectiva de género.

La reflexión sobre nosotros/as mismos/as en el trabajo en ESI es ineludible, y muchas veces movilizante y transformador. Pone de relieve la enorme dificultad que solemos tener para apoderarnos de nuestro cuerpo como nuestro territorio físico, emocional y como nuestro canal de comunicación con el mundo.

En ese marco, durante los últimos años hemos llevado adelante una serie de iniciativas en escuelas secundarias de Rosario y la zona. Ejemplo de ello fue el "Proyecto por Amor a vos", realizado durante 2016 y 2017, destinado a estudiantes de dos establecimientos de la ciudad con condiciones socioeconómicas diferentes.

Asimismo, hemos coordinado espacios de formación y capacitación en derechos de las mujeres, prevención de la violencia de género, derechos sexuales y reproductivos en espacios comunitarios y con funcionarios/as públicos/as de 
diversas áreas municipales y provinciales. También hemos utilizado como herramienta el teatro foro, junto al Grupo teatro de Ixs Oprimidxs (GTO Rosario).

\section{Biblioteca Feminista y producción de materiales de difusión}

Una arista importante en nuestro trabajo de sensibilización y promoción de derechos es la producción de materiales de distribución gratuita; que entregamos principalmente en talleres y acciones de visibilización pública, pero que también nos solicitan referentes comunitarios y educadores para su trabajo territorial.

Sin dudas, "La Chancleta" representa un material que ha servido a estos fines tomando una serie de temáticas de interés para el trabajo de nuestra organización, brindando información actualizada y recursos para las mujeres afectadas. En su primera impresión en 1985, es decir apenas a un año de la fundación de Indeso-Mujer, "La Chancleta" tomó como eje "El trabajo doméstico: un trabajo no remunerado"; poniendo el acento en visibilizar estas tareas y aportar al cuestionamiento de las desigualdades en la organización familiar.

Si tomamos en cuenta el contexto de este material, notaremos que estas producciones eran pioneras en marcar agenda con demandas que aún hoy se debaten. Así lo señala la historiadora Silvia Federici en una entrevista realizada en 2016:

\footnotetext{
"Estamos en un período en el cual se está desarrollando un nuevo tipo de patriarcado en el cual las mujeres no son sólo amas de casa, pero en el que los valores y las estructuras sociales tradicionales aún no han sido cambiadas. Por ejemplo, hoy muchas mujeres trabajan fuera de la casa, muchas veces en condiciones precarias, lo que supone una pequeña fuente de mayor autonomía.

Sin embargo, los lugares de trabajo asalariado no han sido cambiados, lo que significa adaptarse a un régimen que está construido pensado en el trabajo tradicional masculino. Es un nuevo patriarcado en el que las
}

Revista Zona Franca- Centro de estudios interdisciplinario sobre las mujeres (CEIM)- Maestría poder y sociedad desde la problemática de género (MG), Rosario, Argentina. ISSN, 2545-6504 http://zonafranca.unr.edu.ar/index.php/ZonaFrancal Número 28 (2020). 
mujeres deben ser dos cosas: productoras y reproductoras al mismo tiempo, una espiral que acaba consumiendo toda la vida de las mujeres".

Como señalábamos, "La Chancleta" son cuadernillos que durante más de 30 años abordaron temáticas vinculadas a la violencia de género, los derechos sexuales y reproductivos, y la trata de personas. En su última edición (septiembre del 2020), se tomaron como ejes la "ESI y sororidad" con la intención de profundizar en un aspecto poco abordado de la Educación Sexual Integral, pero que nos parece fundamental para prevenir las violencias en los vínculos: las relaciones al interior del colectivo de quienes nos autopercibimos como mujeres (cis o trans).

Además, entre marzo de 1993 y agosto de 1998 se publicó "La Chancleta Informativa", con el fin de "llegar con regularidad a todas las mujeres, reflexionar sobre algunos temas, y contar sobre nuestras actividades y las del movimiento de mujeres en su conjunto".

Fue en esa línea que años más tarde se lanzó el Periódico "Otras Voces". Otra producción importante en la trayectoria de Indeso-Mujer y que se publicó desde marzo de 2010 hasta abril de 2011. En sus páginas se recogen artículos de reconocidas periodistas feministas de la ciudad, así como análisis de coyuntura y de problemáticas que preocupan al movimiento de mujeres. Constituye un verdadero archivo histórico de las luchas y desafíos feministas de esa década.

En ese marco, se editaron diversas investigaciones tales como: "Reconociendo nuestros derechos" (Guía práctica de las leyes en materia de derechos de las mujeres), "Las trampas del silencio" (Investigación sobre feminicidios en Argentina y responsabilidades del Estado), entre otras.

Igualmente, hemos participado en forma activa en campañas de sensibilización en medios gráficos, televisivos y radiales. Ejemplo de ello fue la participación de Indeso-Mujer durante los '80 y '90 en un micro radial en el Programa "Hipótesis"; de mucha audiencia por aquel entonces, ya que Eduardo

Revista Zona Franca- Centro de estudios interdisciplinario sobre las mujeres (CEIM)- Maestría poder y sociedad desde la problemática de género (MG), Rosario, Argentina. ISSN, 2545-6504 http://zonafranca.unr.edu.ar/index.php/ZonaFranca| Número 28 (2020). 
Aliverti viajaba desde Buenos Aires a Rosario para realizarlo en vivo y colaboraban periodistas locales de peso. También hemos sostenido nuestro propio programa, como ocurrió en 2018 con "Feminismos del Sur" en Radio Frida, un espacio comunitario y diverso integrado por una amplia gama de organizaciones.

Mantenemos un permanente intercambio con los espacios de comunicación popular, como parte de las estrategias institucionales que nos damos; además de intentar instalar estos temas en medios hegemónicos.

Precisamente, como parte de estas estrategias, en los últimos años surgió la necesidad de sumar las producciones audiovisuales a los formatos y soportes de registro, difusión y articulación. Frente a la creciente demanda de este tipo de insumos y el uso de las redes sociales, se fueron incorporando herramientas que resultan fundamentales en la actualidad para dar a conocer nuestras actividades y aportar a la promoción de los derechos de las mujeres.

En nuestra página de Facebook (Indeso Mujer), tenemos un alcance orgánico de más de 200 personas por publicación. Es asimismo un canal de diálogo con otras organizaciones y también de consulta permanente, al que escriben mujeres víctimas de diferentes tipos de violencia. Por su parte, en nuestra cuenta en Instagram (@indesomujer) tenemos más de 1.000 seguidores y continúa creciendo la interacción con las publicaciones que hacemos casi a diario. Además, contamos con nuestro canal de YouTube (Indeso Mujer) donde se pueden ver una serie de registros y producciones con contenido pedagógico e informativo.

Finalmente, no podemos pensar la producción de materiales impresos y audiovisuales, sin vincularla al trabajo de nuestra Biblioteca Feminista y archivo de organizaciones sociales. Contamos con una amplia colección de libros y material especializado en estudios sociales y de género, desde títulos clásicos a novedades de investigación contemporánea en estas áreas.

Revista Zona Franca- Centro de estudios interdisciplinario sobre las mujeres (CEIM)- Maestría poder y sociedad desde la problemática de género (MG), Rosario, Argentina. ISSN, 2545-6504 http://zonafranca.unr.edu.ar/index.php/ZonaFranca| Número 28 (2020). 
En la actualidad, nuestra Biblioteca está integrada por aproximadamente 2.000 títulos clasificados en varias categorías: Trabajo, Educación y Cultura, Psicología, Historia, Sexualidad, Feminismos, Política y Participación, Derechos Humanos, Prostitución, Violencia de Género, Aborto, Medios de Comunicación, Infancias, Diversidad y Disidencias Sexuales, Discapacidad; para nombrar algunas. Asimismo, tenemos para consulta una importante colección de revistas y publicaciones especializadas de América Latina, Estados Unidos y Europa.

Con miras a concretar la reapertura de este espacio al público en general, estamos trabajando en su organización interna y generando estrategias de difusión de los materiales existentes. También tenemos previsto un proyecto de Biblioteca Móvil, que busca extender el encuentro con los libros y el fomento de la lectura en clave feminista, en distintos territorios de Rosario. Sin embargo, parte de estas actividades debieron postergarse por el contexto de pandemia por Covid19.

\section{Renovando estrategias y desafíos}

Indeso-Mujer forma parte activa del movimiento feminista de Rosario, el país y la región. Desde sus inicios en la década de los '80, apostó a la construcción de una sociedad más democrática y al reconocimiento de los derechos de las mujeres. Esta impronta ha continuado a lo largo de los años, adaptando las demandas y estrategias a los contextos sociopolíticos actuales; sin perder de vista la búsqueda de igualdad, solidaridad y justicia.

Hemos sido partícipes y co-organizadoras de una amplia gama de actividades de la agenda de las mujeres: 8 de marzo Paro Internacional de Mujeres, Ni Una Menos, 25 de noviembre "Día Internacional de la Eliminación de la Violencia contra las Mujeres", "Agitazo por la ESI”, entre otras.

Asimismo, estuvimos en las simientes del Primer Encuentro Nacional de Mujeres (ENM), que se realizó en la ciudad de Buenos Aires en mayo de 1986 y

Revista Zona Franca- Centro de estudios interdisciplinario sobre las mujeres (CEIM)- Maestría poder y sociedad desde la problemática de género (MG), Rosario, Argentina. ISSN, 2545-6504 http://zonafranca.unr.edu.ar/index.php/ZonaFranca| Número 28 (2020). 
contó con una Comisión Organizadora integrada por 43 mujeres provenientes de variados sectores sociales y políticos. En agosto de 1989, la sede del Encuentro tuvo lugar en Rosario y las integrantes de Indeso-Mujer fueron parte de esa organización.

A continuación, reproducimos un fragmento del discurso de apertura del $4^{\circ}$ ENM:

"El momento histórico que nos toca vivir es uno de los más dramáticos debido a la crisis económica que azota a nuestro país y que afecta con mayor fuerza a los sectores más desposeídos y en particular a las mujeres, porque nosotras vivimos a diario esta crisis, somos las amas de casa que hacemos milagros para cubrir los gastos familiares, somos las víctimas de la especulación y la falsa publicidad, somos también las madres a las que nos aflige el futuro de nuestros hijos.

Pero más allá de esta crisis, no podemos olvidar problemas que nos afectan especialmente en nuestra condición de mujeres, y que hemos sufrido siempre, aún en épocas de bonanza: porque nosotras somos desde siempre las que padecemos la violencia familiar, los golpes e insultos cotidianos, las violaciones. Somos también las que soportamos la doble jornada, las primeras en ser despedidas, las que cobramos salarios menores, las que sufrimos discriminaciones en nuestros trabajos. Somos nosotras también las que cargamos casi en exclusividad con la responsabilidad de la reproducción de la sociedad, y somos criticadas cuando exigimos una responsabilidad compartida"VIII.

Estas palabras no pierden fuerza ni vigencia, a más de 30 años de pronunciarse frente a miles de mujeres. Lo mismo ocurrió en el $18^{\circ}$ ENM que volvió a encontrarnos en Rosario con la bandera del "aborto legal, seguro y gratuito", como señalábamos en un apartado anterior. $O$ bien en el $31^{\circ}$ ENM que se realizó en octubre de 2016 en la ciudad y tuvo una participación multitudinaria.

VIII El discurso de apertura del IV Encuentro Nacional de Mujeres fue compartido en el segmento que tenían nuestra institución en el programa radial "Hipótesis".

Revista Zona Franca- Centro de estudios interdisciplinario sobre las mujeres (CEIM)- Maestría poder y sociedad desde la problemática de género (MG), Rosario, Argentina. ISSN, 2545-6504 http://zonafranca.unr.edu.ar/index.php/ZonaFrancal Número 28 (2020). 
Sin embargo, este 2020 no pudimos acudir a ese multitudinario ritual de militancia, organización popular y lucha. La pandemia de Covid-19 y las medidas adoptadas por los gobiernos en medio de una crisis sanitaria, han afectado fuertemente el actual contexto.

Esto impacta directamente en la vida cotidiana de la sociedad en su conjunto, especialmente en los sectores más vulnerables que no acceden a determinados derechos. Las mujeres y niñas pertenecen a ese grupo de riesgo, quienes ven mayormente expuesta su integridad (física y emocional) al tener que transitar el aislamiento social encerradas con sus agresores y abusadores.

Según un relevamiento realizado por MumalálX (Mujeres de la Matria Latinoamericana), durante los primeros 6 meses de aislamiento (del 20 de marzo al 20 de septiembre de 2020) se registraron 127 femicidios en Argentina: es decir, 1 asesinato por razones de género cada 34 horas. En el 65\% de los casos, el agresor fue la pareja o la ex pareja de la víctima; mientras que el $71 \%$ de los femicidios fueron en la vivienda de la víctima.

Frente a este nuevo escenario, nos vimos en la necesidad adaptar nuestras acciones a formatos virtuales de difusión, articulación e incidencia. Las herramientas y dispositivos digitales han sido canales fundamentales para llegar a la comunidad y generar sinergias con otras organizaciones. Incluso, se crearon nuevos espacios de trabajo, que se sumaron a los ya existentes, tales como: el Comité Feminista para la Emergencia Sanitaria, el Consejo Asesor de la Comisión de Feminismos y Disidencias del Concejo Municipal.

Al mismo tiempo, aumentaron las consultas de mujeres de diferentes edades y clases sociales para recibir asesoramiento integral gratuito, en casos de violencia de género (física, emocional, económica, entre otras). Se trata de un espacio que apunta a brindar herramientas a las mujeres, cuya situación se agravó en el aislamiento obligatorio por coronavirus. La metodología utilizada es la

Ix Disponible en https://www.facebook.com/MumalaNacional

Revista Zona Franca- Centro de estudios interdisciplinario sobre las mujeres (CEIM)- Maestría poder y sociedad desde la problemática de género (MG), Rosario, Argentina. ISSN, 2545-6504 http://zonafranca.unr.edu.ar/index.php/ZonaFranca| Número 28 (2020). Página 568 
entrevista personal pautada con anticipación, para ofrecer privacidad y escucha respetuosa.

En lo que va de 2020, hemos respondido unas 50 consultas por correo electrónico, teléfono y redes sociales. Se lleva adelante una ficha de seguimiento de cada caso, para un mejor monitoreo y evaluación de los pasos a seguir. Además, se informa sobre los recursos y dispositivos estatales disponibles; al tiempo que se generan articulaciones con las áreas municipales pertinentes, para garantizar la seguridad y bienestar de la víctima.

Hoy, como hace 36 años, seguimos trabajando por los derechos de las mujeres. Afirmamos que cada persona interpelada, cada actividad y cada espacio que nace desde la articulación con otras organizaciones y el trabajo territorial, tienen un gran potencial transformador.

Quienes integramos hoy Indeso-Mujer heredamos este legado que nos dejaron las fundadoras, una gran responsabilidad pero también una bandera que llevamos con orgullo y un profundo agradecimiento.

\section{Bibliografía}

DILLON Marta (2004). "Mujeres en llamas", en el diario Página/12. Disponible en https://www.pagina12.com.ar/diario/suplementos/las12/13-1527-2004-10-

\section{5.html}

FEDERICI Silvia (2016). "Tenemos que empezar una lucha sobre qué significa el trabajo doméstico". Revista La Tinta.

FEMINISMOS DEL SUR, programa radial emitido en Radio Frida el12 de mayo de 2018. Disponible en https://youtu.be/Zfp1gLE8bsU

GABARRA, Mabel (1995). "Una experiencia de concertación en el Centro de Mujeres Juana Azurduy, de Rosario, Argentina", en Dialogues, proposals, storiesfor global citizenship №12. Disponible en http://base.d-ph.info/en/fiches/premierdph/fiche-premierdph-2398.html

Revista Zona Franca- Centro de estudios interdisciplinario sobre las mujeres (CEIM)- Maestría poder y sociedad desde la problemática de género (MG), Rosario, Argentina. ISSN, 2545-6504 http://zonafranca.unr.edu.ar/index.php/ZonaFrancal Número 28 (2020). 
INDESO-MUJER (1993). "La Chancleta Informativa" №1. Rosario, Argentina INDESO-MUJER (2005). Periódico "Otras Voces" N 53. Rosario, Argentina. INDESO-MUJER (2019). "La Chancleta" sobre "Derechos Sexuales y Reproductivos". Disponible en https://my.flipbookpdf.net/XRinE

INDESO-MUJER (2020). "La Chancleta" sobre "ESI y sororidad". Disponible en https://my.flipbookpdf.net/XRinE

RIVERO Mónica, OLIVERA Juan Facundo (2016). "Aprendizajes y conclusiones desde las organizaciones. Sistematización de experiencias 20112016". Valija Pedagógica, Plataforma Mercosur Social y Solidario (PMSS). Disponible en http://valijapedagogica.mercosursocialsolidario.org/herramientasconceptuales/08-sistematizacion-de-los-encuentros-de-frontera-pmss.htm

SELVA Beatriz (1989). "Reconociendo nuestra realidad". Cuadernos de divulgación. $\mathrm{N}^{\circ} 8$.

TESSA Sonia (2005). "Poniéndoles la firma a sus derechos", en el diario Rosario/12

Revista Zona Franca- Centro de estudios interdisciplinario sobre las mujeres (CEIM)- Maestría poder y sociedad desde la problemática de género (MG), Rosario, Argentina. ISSN, 2545-6504 http://zonafranca.unr.edu.ar/index.php/ZonaFrancal Número 28 (2020). 